University of South Carolina

Scholar Commons

7-2005

\title{
Psychometric Properties of the Self-Efficacy for Exercise Questionnaire in a Diverse Sample of Men and Women
}

\author{
Sarah Wilcox \\ University of South Carolina - Columbia, swilcox@sc.edu \\ Patricia A. Sharpe \\ University of South Carolina - Columbia, SHARPEP@mailbox.sc.edu \\ Brent E. Hutto \\ Michelle L. Granner
}

Follow this and additional works at: https://scholarcommons.sc.edu/

sph_physical_activity_public_health_facpub

Part of the Public Health Commons

\section{Publication Info}

Published in Journal of Physical Activity and Health, Volume 2, Issue 3, 2005, pages 285-297.

Wilcox, S., Sharpe, P. A., Hutto, B., \& Granner, M. L. (2005). Psychometric properties of the self-efficacy for exercise questionnaire in a diverse sample of men and women. Journal of Physical Activity and Health, 2(3), 285-297.

(c) Journal of Physical Activity and Health, 2005, Human Kinetics

This Article is brought to you by the Physical Activity and Public Health at Scholar Commons. It has been accepted for inclusion in Faculty Publications by an authorized administrator of Scholar Commons. For more information, please contact digres@mailbox.sc.edu. 


\title{
Psychometric Properties of the Self-Efficacy for Exercise Questionnaire in a Diverse Sample of Men and Women
}

\author{
Sara Wilcox, Patricia A. Sharpe, \\ Brent Hutto, and Michelle L. Granner
}

\begin{abstract}
Background: Self-efficacy is a consistent correlate of physical activity, but most self-efficacy measures have not been validated in diverse populations. This study examined the construct, criterion-related, and convergent validity and internal consistency of the Self-Efficacy for Exercise Questionnaire. Methods: African American and Caucasian adults $(N=1919)$ from two adjacent counties in South Carolina were identified through a list-assisted random digit-dialed telephone survey. Psychometric properties of the measure were assessed by gender, race, age, education, and body weight subgroups. Results: Across all subgroups, a single-factor solution explained 93 to $98 \%$ of the common variance in an exploratory factor analysis, and all 14 items had factor loadings exceeding 0.40 . Higher exercise self-efficacy was significantly associated with greater physical activity, younger age, male gender, higher education, and lower body weight, as predicted. Internal consistency was high for all subgroups $(\alpha=0.90$ to 0.94). Conclusion: The Self-Efficacy for Exercise Questionnaire appears to be a valid and reliable measure for use with diverse populations.
\end{abstract}

Self-efficacy is a key construct in social cognitive theory ${ }^{1-4}$ and refers to a person's beliefs in his or her abilities to execute a plan of behavior. Although developed as part of social cognitive theory, self-efficacy has been incorporated into many other behavior theories, including the health belief model ${ }^{5}$ and the transtheoretical model. ${ }^{6}$ Self-efficacy is theorized to influence the types of activities an individual chooses, the effort expended on the activity, and the persistence of one's behavior when faced with challenges. ${ }^{1}$ Self-efficacy for exercise is a consistently reported correlate of physical activity and exercise participation. ${ }^{7}$ The association between self-efficacy and physical activity has been documented in diverse populations, including college-aged adults, ${ }^{8}$ women, ${ }^{9}$ ethnically diverse populations, ${ }^{10,}{ }^{11}$ and older adults. ${ }^{12,13}$

Several exercise self-efficacy measures have been developed for use with general adult populations in the physical activity literature. ${ }^{14}$ These measures range

The authors are with the Arnold School of Public Health, University of South Carolina, Columbia, SC 29208. Wilcox and Sharpe are with the school's Dept of Exercise Science. Sharpe, Hutto, and Granner are also with the school's Prevention Research Center. Granner is also with the school's Dept of Health Promotion, Education, and Behavior. 
from single- to multi-item, and most commonly measure exercise efficacy (i.e., perceived ability to engage in incremental bouts of exercise), barriers efficacy (i.e., perceived ability to overcome barriers to exercising), or disease-specific measures (i.e., perceived ability to engage in exercise as a self-management strategy for disease management). Relatively few studies of barrier self-efficacy exist, and while several of these measures have received psychometric study, ${ }^{15-17}$ the properties of these scales in more diverse populations have not been reported.

Researchers at Stanford University developed an exercise self-efficacy scale that has been shown to predict exercise behavior over time in the context of an intervention. ${ }^{18,19}$ Only the internal consistency, test-retest reliability, and criterionrelated validity of this scale have been reported, however, and they were reported in a sample that was middle to older age and primarily Caucasian and well-educated. Thus, the purpose of this study was to examine the psychometric properties of the Self-Efficacy for Exercise Questionnaire, specifically, construct validity, concurrent criterion-related validity, convergent validity, and internal consistency in a diverse population. Our study is the first to report on the factor structure of this measure and the psychometric properties in a large and diverse sample. We included a large community-based sample that allowed us to examine psychometric properties by demographic and body weight (determined by body-mass index) groups. In the interventions noted earlier, the authors have treated this measure as representing a single construct or factor. We believe it is important to determine whether the scale in fact represents one or more factors. Thus, factor analysis was the major analytic approach chosen for this study. Although we had no specific predictions regarding whether the factor structure and psychometric properties of this scale would differ by demographic and body weight groups, given the emphasis on health disparities, the need to show that scales are appropriate in diverse populations is practically important.

A consistent relationship between self-efficacy and physical activity has been reported, ${ }^{7}$ thus, we hypothesized that individuals with higher self-efficacy would report higher levels of physical activity participation. While fewer studies have specifically examined other predictors of self-efficacy, a number of studies have shown that age is negatively associated ${ }^{20-23}$ while socioeconomic status is positively associated ${ }^{23,24}$ with self-efficacy. In older adult populations, men have been shown to have higher self-efficacy than women. ${ }^{24-26}$ Thus, we hypothesized that age would be negatively associated and education and male gender would be positively associated with self-efficacy. Finally, although there is little evidence regarding race and body-mass index, we hypothesized that African Americans would report lower self-efficacy than Caucasians and individuals with a higher body-mass index would report lower self-efficacy than leaner adults as both of these variables are associated with physical activity.?

\section{Method}

\section{Participants and Procedures}

Surveys were conducted with adults residing in two adjacent counties in South Carolina. Data from the 2000 Census indicate that the populations of these 2 counties are 104,646 and 125,781, respectively. The average household size is 2.68 and 2.59 persons; $49.9 \%$ and $41.3 \%$ of residents are ethnic minorities (predominantly 
African American); $11.2 \%$ and $11.8 \%$ are age $65 \mathrm{y}$ or older, and $48.4 \%$ and $49.3 \%$ are men. According to 1990 data (most recent data available), 58.9\% and $52.3 \%$ of these counties are considered urban.

A list-assisted random digit-dialed telephone survey was conducted with 2025 non-institutionalized adults age $18 \mathrm{y}$ and older residing in telephone-equipped dwellings. The average length of the interview was $18.6 \mathrm{~min}$. The survey was conducted by ORC Macro of Burlington, VT. After determining whether a private residence was reached, participants were asked, "Of the people who currently live in your household who are 18 or older, including yourself, we would like to interview the one who will have the next birthday. Would that be you or someone else?" The individual with the next birthday was interviewed. Interviews occurred between May 15 and June 23, 2003.

At least 15 attempts were made to reach unanswered calls, at multiple times of day and days of the week. Once contact was made, as many calls as necessary were made to reach the selected adult. Initial refusals were recontacted after $3 \mathrm{~d}$ by specially trained interviewers in an effort to reverse the refusal. At least $10 \%$ of interviews were monitored for quality assurance. Data were entered via a Computer Assisted Telephone Interview database. The Council of American Survey Research Organizations (CASRO) formulae represent a common approach for computing response rates. The CASRO response rate computes the rate at which interviews are accomplished among all identified, potentially eligible respondents, in addition to households for which eligibility could not be determined. The upper bound, or cooperation rate, is computed as I / I $+R$, where $\mathrm{I}$ is the number of interviews and $\mathrm{R}$ is the number of refusals. It measures the level of cooperation among identified, eligible, and capable respondents. A lower bound for the response rate, a measure of the sample frame efficiency, is computed as I/(Total Sample) and shows the rate at which the total sample produces completed interviews. The upper bound was $19.91 \%$, lower bound $6.05 \%$, and CASRO rate $16.25 \% .{ }^{27}$

The survey's weights were calculated using post-stratification factor adjusting weighted totals to 2000 census population figures by age, race/ethnicity, and gender. Given the sampling design and the attendant weighting, the overall precision of the sample is $+1.10 \%$, with an average design effect of 0.83 .

\section{Measures}

Self-Efficacy. The Self-Efficacy for Exercise Questionnaire was developed at Stanford University in collaboration with Albert Bandura. ${ }^{18}$ The scale consists of 14 items that ask participants to rate their confidence to exercise (ranging from $0 \%$ to $100 \%$ ) when faced with commonly-cited barriers (e.g., when tired, depressed, have a lot of work to do, etc.). Ratings across the 14 items are averaged to form a composite scale. In a sample of primarily Caucasian and well-educated adults age 50 to $65 \mathrm{y}$ participating in an exercise intervention study, ${ }^{18}$ the scale was shown to have high internal consistency (Cronbach's alpha $=0.90)$ and 12-month test-retest reliability ( $r=0.67$ ). Further, self-efficacy was predictive of exercise adherence during months 1 to 6 and 7 to 12 of the trial, providing support for concurrent criterion-related validity. More recently, changes in self-efficacy from baseline to 6 months as well as absolute levels of self-efficacy at 6 months were associated with exercise adherence in months 7 through 12 in a sample of adults age $65 \mathrm{y}$ and older who were primarily Caucasian and well-educated participating in an exercise 
intervention. ${ }^{19}$ We chose to examine this scale in more detail, relative to other selfefficacy scales, because it taps a broad range of barriers, has been shown to mediate intervention effects, and has not received critical psychometric investigation.

Physical Activity. Physical activity was assessed with the moderate and vigorous physical activity questions of the 2001 version of the Behavioral Risk Factor Surveillance System (BRFSS) Physical Activity module. The BRFSS is a telephoneadministered survey completed annually with residents of all states, the District of Columbia, and three US territories. The physical activity module, which is a required module on alternating years, assesses moderate and vigorous physical activity (frequency and duration) and is used to monitor current levels of physical activity participation as well as trends over time. A recent study comparing an objective physical activity measure (i.e., simultaneous heart-rate motion sensor technique) with the BRFSS physical activity module reported $80 \%$ agreement between the 2 methods of classifying individuals who met the current Centers for Disease Control and Prevention-American College of Sports Medicine (CDCACSM) recommendations..$^{28}$

Using 3 questions, the BRFSS physical activity module asked respondents whether in a usual week they participated in moderate activities for at least $10 \mathrm{~min}$ at a time, and if so, the number of days and total time per day spent in these activities. The same questions were repeated to assess vigorous activities. For both moderate and vigorous activities, examples were provided to participants. Using the CDC scoring algorithms, participants were classified into one of three groups consistent with CDC-ACSM recommendations: $:^{29} 1$ ) regularly active - participated in moderate activities 5 or more days per week for 30 or more minutes per day or vigorous activities 3 or more days per week for 20 or more minutes per day; 2) irregularly active - participated in at least 10 min of moderate or vigorous physical activity in a usual week, but at a frequency or duration that did not meet the regularly active definition; or 3) inactive-participated in no physical activities for more than $10 \mathrm{~min}$ in a usual week.

Demographics. Respondents were asked to report their age, race, gender, highest grade completed, and height and weight (body-mass index was calculated as $\mathrm{kg} / \mathrm{m}^{2}$ ).

\section{Data Analysis}

Analyses were conducted using SAS version 8.0 for the PC (SAS Institute, Cary, NC). All analyses described below were first conducted with the entire sample, and then analyses were conducted by gender (men and women), race (African American and Caucasian), age (18 to 34,35 to 54, and 55+y), weight (normal weight, overweight, and obese), and educational level (less than high school, high school graduate, some college, and college graduate). We also examined psychometric properties for 4 groups: African American women, African American men, Caucasian men, and Caucasian women.

Factor Structure. An exploratory factor analysis was conducted with responses to the 14-item questionnaire using squared multiple correlations as prior communality estimates. The principal factor method was used. If more than 1 factor was extracted, we planned to follow the principal factor method with a promax (oblique) 
rotation. The number of meaningful factors was determined by the scree test and proportion of explained variance. The scree test was visually examined for natural breaks in factors and a factor had to explain at least $10 \%$ of the common variance to be identified as a unique factor. In order for an item to be labeled as loading on a factor, the item loadings had to exceed 0.40 .

Internal Consistency. Cronbach's alpha was computed to assess the internal consistency of the questionnaire. We also examined whether the alpha levels could be improved by deleting items.

Concurrent Criterion-Related and Convergent Validity. The association between self-efficacy (independent variable) and physical activity category (dependent variable) was assessed using a multinomial logistic regression model using the proportional odds assumption. We computed the pseudo- $R^{2}$ using the formula recommended by Magee. ${ }^{30} \mathrm{We}$ also examined the associations between self-efficacy (dependent variable) and body-mass index, age, race, and education (independent variables) using analyses of variance (ANOVA) (one ANOVA for each demographic variable). Group differences were examined using Tukey HSD pairwise comparisons. Differences by gender and race were examined with $t$-tests.

\section{Results}

\section{Sample}

Because less than 5\% ( $n=106$ of 2025) of the total sample was of a race/ethnicity other than Caucasian or African American, we restricted all analyses to Caucasians and African Americans $(N=1919)$. The demographic characteristics of respondents are shown in Table 1. Over half of the participants were women (58\%) and 66\% were Caucasian. Participants were fairly evenly distributed across age, education, and body weight groups, although there was a somewhat lower percentage of respondents without a high school diploma $(11 \%)$ relative to other education groups (30\% high school graduates, $31 \%$ some college, and $28 \%$ college graduates). Just over half of participants (52\%) met the CDC-ACSM recommendations for regular physical activity, $35 \%$ were irregularly active, and $9 \%$ were inactive.

\section{Factor Analysis}

The results of the exploratory factor analyses were consistent across gender, race, age, weight, and education groups. Although the analysis suggested the possibility of a two-factor solution to the data, the scree test and an examination of common variance explained by factors indicated that a one-factor solution was most parsimonious. The scree test indicated one meaningful factor, and the eigenvalue was 6.65 for the first factor, but only 0.40 for the second factor. Furthermore, across subgroups, the common variance explained by the single-factor solution ranged from $93 \%$ to $98 \%$. Thus, a promax rotation was not deemed necessary.

The factor analysis also indicated that all items should be retained as each had a factor loading that exceeded 0.40 . The factor loadings for each item and the proportion of common variance explained by the single-factor solution for each subgroup are shown in Table 2 . The one item that loaded somewhat lower than the other items was the respondents' confidence they could exercise when on vacation. 
Table 1 Demographic Characteristics of the Sample $(N=1919)$

\begin{tabular}{|c|c|c|}
\hline Characteristic & $n$ & $\%$ of sample \\
\hline \multicolumn{3}{|l|}{ Gender } \\
\hline Women & 1112 & 58 \\
\hline Men & 753 & 39 \\
\hline Missing & 54 & 3 \\
\hline \multicolumn{3}{|l|}{ Race } \\
\hline African American & 658 & 34 \\
\hline Caucasian & 1261 & 66 \\
\hline \multicolumn{3}{|l|}{ Age } \\
\hline $18-34 \mathrm{y}$ & 641 & 33 \\
\hline $35-54 y$ & 790 & 41 \\
\hline $55+y$ & 449 & 23 \\
\hline Missing & 39 & 2 \\
\hline \multicolumn{3}{|l|}{ Education } \\
\hline Less than high school & 213 & 11 \\
\hline High school graduate & 574 & 30 \\
\hline Some college & 591 & 31 \\
\hline College graduate & 531 & 28 \\
\hline Missing & 10 & $<1$ \\
\hline \multicolumn{3}{|l|}{ Body-mass index } \\
\hline Underweight $\left(<18.5 \mathrm{~kg} / \mathrm{m}^{2}\right)$ & 33 & 2 \\
\hline Normal weight $\left(18.5-24.9 \mathrm{~kg} / \mathrm{m}^{2}\right)$ & 689 & 36 \\
\hline Overweight $\left(25.0-29.9 \mathrm{~kg} / \mathrm{m}^{2}\right)$ & 646 & 34 \\
\hline Obese $\left(\geq 30.0 \mathrm{~kg} / \mathrm{m}^{2}\right)$ & 440 & 23 \\
\hline Missing & 111 & 6 \\
\hline \multicolumn{3}{|l|}{ Physical activity level } \\
\hline Inactive & 171 & 9 \\
\hline Underactive & 664 & 35 \\
\hline Regularly active & 998 & 52 \\
\hline Missing & 86 & 4 \\
\hline
\end{tabular}

Note: Due to rounding, percentages may not total $100 \%$.

The factor loading for this item, however, was still relatively high and ranged from 0.42 to 0.65 across groups.

We also examined the factor structure in African American women, Caucasian women, African American men, and Caucasian men, and the same results on the scree tests, tests of explained variance, and factor loadings were shown for each group.

\section{Reliability}

Internal consistency was high for every subgroup of the sample, with Cronbach's alpha ranging from 0.90 to 0.94 . These results are shown in Table 2. The Cronbach's 


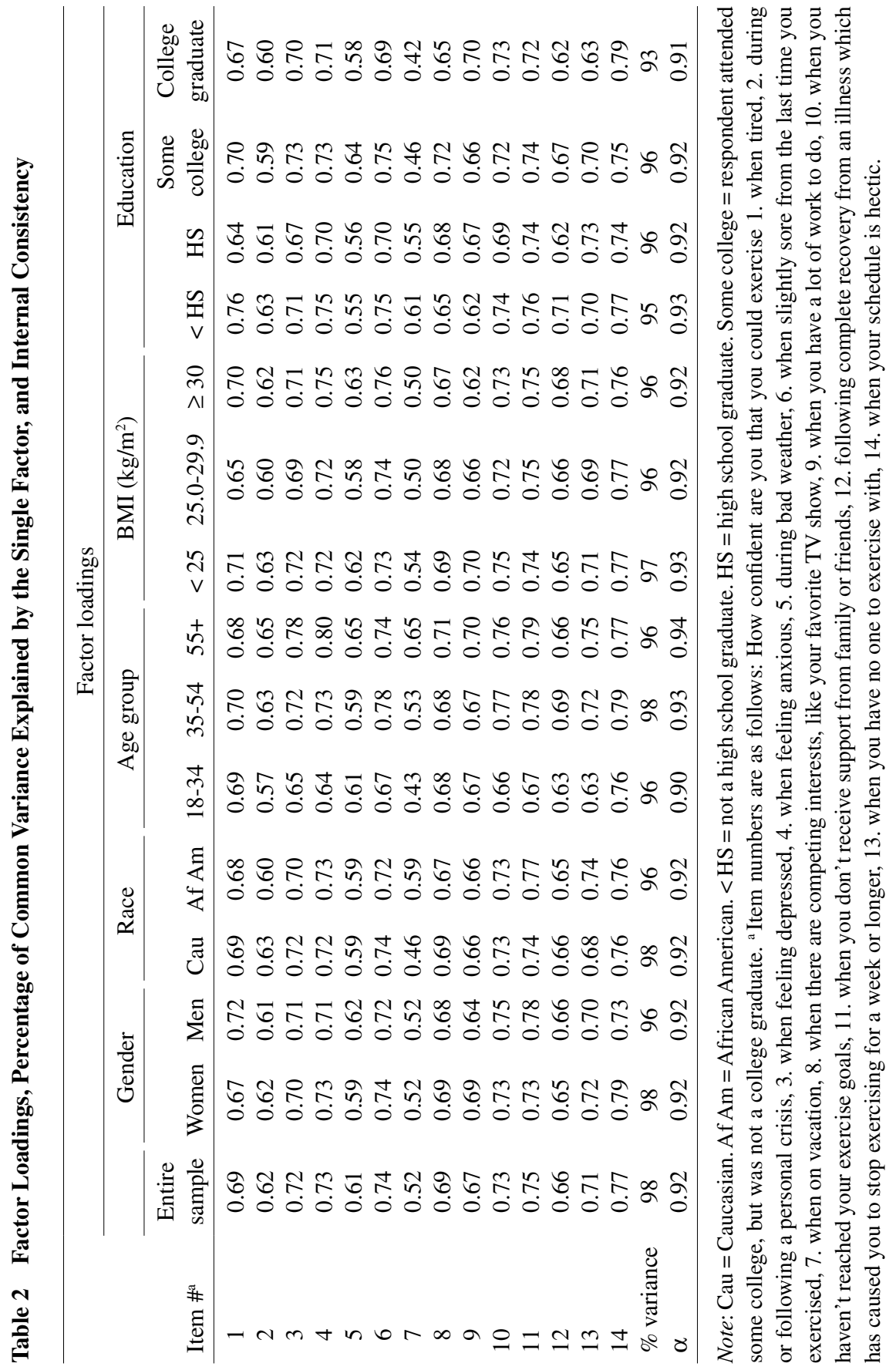


alphas for the race by gender subgroups were: 0.91 for African American women $(n=414), 0.92$ for Caucasian women $(n=526), 0.93$ for African American men $(n=226)$, and 0.91 for Caucasian men $(n=526)$. Alpha was not increased by the removal of any scale items for any of the subgroups examined. The intercorrelations among the 14 items are shown in Table 3.

Table 3 Intercorrelations (Pearson) Between Self-Efficacy Items for the Entire Sample $(N=1918)$

\begin{tabular}{|c|c|c|c|c|c|c|c|c|c|c|c|c|c|}
\hline & 2 & 3 & 4 & 5 & 6 & 7 & 8 & 9 & 10 & 11 & 12 & 13 & 14 \\
\hline 1 & 0.51 & 0.55 & 0.53 & 0.46 & 0.52 & 0.35 & 0.47 & 0.49 & 0.46 & 0.46 & 0.43 & 0.42 & 0.53 \\
\hline 2 & & 0.59 & 0.55 & 0.37 & 0.42 & 0.32 & 0.39 & 0.38 & 0.42 & 0.40 & 0.38 & 0.38 & 0.45 \\
\hline 3 & & & 0.60 & 0.41 & 0.50 & 0.34 & 0.47 & 0.44 & 0.52 & 0.50 & 0.44 & 0.46 & 0.52 \\
\hline 4 & & & & 0.44 & 0.55 & 0.33 & 0.49 & 0.42 & 0.55 & 0.54 & 0.46 & 0.50 & 0.51 \\
\hline 5 & & & & & 0.49 & 0.27 & 0.44 & 0.41 & 0.43 & 0.43 & 0.41 & 0.40 & 0.49 \\
\hline 6 & & & & & & 0.36 & 0.51 & 0.46 & 0.57 & 0.57 & 0.52 & 0.54 & 0.54 \\
\hline 7 & & & & & & & 0.40 & 0.42 & 0.37 & 0.38 & 0.35 & 0.38 & 0.40 \\
\hline 8 & & & & & & & & 0.51 & 0.54 & 0.51 & 0.44 & 0.45 & 0.52 \\
\hline 9 & & & & & & & & & 0.47 & 0.44 & 0.44 & 0.40 & 0.65 \\
\hline 10 & & & & & & & & & & 0.60 & 0.48 & 0.55 & 0.54 \\
\hline 11 & & & & & & & & & & & 0.53 & 0.68 & 0.56 \\
\hline 12 & & & & & & & & & & & & 0.53 & 0.53 \\
\hline 13 & & & & & & & & & & & & & 0.55 \\
\hline
\end{tabular}

\section{Concurrent Criterion-Related and Convergent Validity}

In the multinomial logistic regression model, the proportional odds assumption was not violated, indicating that this test was appropriate to interpret. Self-efficacy significantly predicted physical activity category membership (inactive, irregularly active, or regularly active) in the entire sample, Wald $\chi^{2}(1, N=1931)=266.54$, $P<0.0001$, pseudo- $R^{2}=0.14$, and in every subgroup. For the sample as a whole, a person in the highest quartile of self-efficacy had a 0.31 odds of being in a loweractivity group than a person in the lowest quartile of self-efficacy. The odds ratio was the same when comparing inactive to other groups or inactive plus irregularly active to meeting recommendations.

Table 4 shows mean self-efficacy scores according to sociodemographic variables (separate ANOVAs or $t$-tests were computed for each variable, with Tukey HSD pairwise comparisons). Significant group differences in self-efficacy were found for gender, race, age, weight category, and education in the predicted directions (Table 4). Women reported lower self-efficacy than men, and African American respondents reported lower self-efficacy than Caucasian respondents. Self-efficacy declined with increasing age, with adults age 55 and older having significantly lower self-efficacy than the younger two age groups $(P<0.05)$. Normal weight respondents and overweight respondents reported higher self-efficacy than 
Table 4 Self-Efficacy Scores for Sample Subgroups

\begin{tabular}{|c|c|c|c|c|}
\hline Sample characteristic & Mean \pm SD & $d f$ & $F($ or $t)$ & $P$ \\
\hline \multicolumn{5}{|l|}{ Gender } \\
\hline Women & $52.25 \pm 24.32$ & \multirow[t]{2}{*}{1,1863} & \multirow[t]{2}{*}{-7.74} & \multirow[t]{2}{*}{$<0.0001$} \\
\hline Men & $61.05 \pm 23.78$ & & & \\
\hline \multicolumn{5}{|l|}{ Race } \\
\hline Caucasian & $59.43 \pm 23.36$ & \multirow{2}{*}{1,1965} & \multirow{2}{*}{-7.93} & \multirow[t]{2}{*}{$<0.0001$} \\
\hline African American & $49.36 \pm 24.92$ & & & \\
\hline \multicolumn{5}{|l|}{ Age } \\
\hline $18-34$ y & $58.52 \pm 22.10_{a}$ & \multirow[t]{3}{*}{2,1877} & \multirow[t]{3}{*}{10.91} & \multirow[t]{3}{*}{$<0.0001$} \\
\hline $35-54 y$ & $56.43 \pm 24.32$ & & & \\
\hline $55+y$ & $51.64 \pm 26.55_{b}$ & & & \\
\hline \multicolumn{5}{|l|}{ Body-mass index } \\
\hline Normal weight $\left(<25.0 \mathrm{~kg} / \mathrm{m}^{2}\right)$ & $59.39 \pm 24.46_{a}$ & \multirow[t]{3}{*}{2,1805} & \multirow[t]{3}{*}{22.68} & \multirow[t]{3}{*}{$<0.0001$} \\
\hline Overweight $\left(25.0-29.9 \mathrm{~kg} / \mathrm{m}^{2}\right)$ & $57.48 \pm 23.53_{\mathrm{a}}$ & & & \\
\hline Obese $\left(\geq 30.0 \mathrm{~kg} / \mathrm{m}^{2}\right)$ & $49.81 \pm 24.31_{b}$ & & & \\
\hline \multicolumn{5}{|l|}{ Education } \\
\hline Less than high school & $44.65 \pm 26.39$ a & \multirow[t]{4}{*}{3,1905} & \multirow[t]{4}{*}{50.56} & \multirow[t]{4}{*}{$<0.0001$} \\
\hline High school graduate & $51.13 \pm 23.74_{b}$ & & & \\
\hline Some college & $57.08 \pm 23.91_{c}$ & & & \\
\hline College graduate & $64.85 \pm 21.25_{\mathrm{d}}$ & & & \\
\hline \multicolumn{5}{|l|}{ Physical activity } \\
\hline Inactive & $37.79 \pm 25.03_{\mathrm{a}}$ & \multirow[t]{3}{*}{2,1830} & \multirow[t]{3}{*}{151.60} & \multirow[t]{3}{*}{$<0.0001$} \\
\hline Irregularly active & $49.09 \pm 22.42_{b}$ & & & \\
\hline Regularly active & $64.12 \pm 22.17_{c}$ & & & \\
\hline
\end{tabular}

Note: Subscripts with different subscript letters are significantly different, based on Tukey HSD pairwise comparisons, $P<0.05$.

obese respondents $(P<0.05)$. As level of education increased, so did self-efficacy $(P<0.05)$. Follow-up tests indicated that each education group differed significantly from the others on self-efficacy $(P<0.05)$. For completeness, we also included self-efficacy scores according to physical activity categories. Follow-up tests indicated that each physical activity category differed significantly from the others on self-efficacy $(P<0.05)$.

\section{Discussion}

Self-efficacy is a theoretical construct central to social cognitive theory, ${ }^{1}$ and it is included in many other theories of behavior change. Self-efficacy is a consistent correlate of physical activity. ${ }^{7}$ Theoretically-based interventions often focus on increasing self-efficacy, and increases in self-efficacy have been shown to translate into increases in physical activity behavior (i.e., self-efficacy is a mediator of physical activity change).$^{19}$ While our knowledge of theoretical constructs and mediators in the general physical activity literature has certainly grown over time, our knowledge 
of these issues in samples that are more diverse in terms of race, ethnicity, and socioeconomic status is limited. ${ }^{31}$ As the field continues to expand to more diverse populations, it is critical to demonstrate the reliability and validity of measures prior to their use. Because self-efficacy is one of the most studied constructs in the field of physical activity behavior, we chose to examine the psychometric properties of one such measure, the Self-Efficacy for Exercise Questionnaire. This scale was chosen for more in-depth psychometric study because it is one of only several scales that has been shown to act as a mediator of physical activity interventions, ${ }^{19}$ has been shown to have good internal consistency and test-retest reliability, but has not been subject to factor analysis, and its psychometric properties have not been reported in diverse populations.

Our sample consisted of both African American and Caucasian adults from 2 counties in South Carolina. The large sample size allowed us to examine the psychometric properties of this measure by age, gender, race, education, and weight status. We also examined the psychometric properties in African American women, African American men, Caucasian men, and Caucasian women separately. Our analyses provided consistent support for the reliability and validity of this measure in each of the sample strata. As it has been used in other studies with older adults, ${ }^{18,19}$ our study indicated that a one-factor measure was appropriate, with all items loading heavily on the factor. The one item with the lowest factor loading was self-efficacy to exercise while traveling, but this item still exceeded a loading of 0.40 . The single factor explained $98 \%$ of the common variance. In each subgroup, we also found that self-efficacy was significantly and positively associated with physical activity participation, consistent with a large body of literature. ${ }^{7}$ Self-efficacy was also associated with other variables we hypothesized and consistent with the literature regarding correlates of self-efficacy and physical activity, including younger age, ${ }^{20-23}$ male gender, ${ }^{24-26}$ higher education, ${ }^{23,24}$ and lower body weight. ${ }^{3}$ Thus, our analyses support the measure's construct, criterion-related, and convergent validity across all subgroups. In addition, the measure was found to have high internal consistency for all groups. Unfortunately, we were unable to measure test-retest reliability of the measure.

Although the representative sampling approach and the large and diverse sample were clear strengths of the study, perhaps the most significant limitation was the low response rate. This response rate was lower than for other surveys we have conducted in the past in similar geographical areas ${ }^{32}$ and was lower than most surveys have reported in the literature. A professional survey organization conducted all surveys and standard methods were used to reach respondents (e.g., multiple calls, calling at different times of the day, calls to refusals, etc.). This survey organization used a system in which there is a delay between when a potential respondent answers the phone and when the interviewer comes on the line, and a large number of nonresponses were the result of the individual hanging up prior to determining their eligibility (this number was larger than the number refusing to participate after determining eligibility). Many individuals might have thought that the telephone call was a telemarketer. The low response rate does cause concern that the sample might be biased in certain ways. For example, the respondents might be healthier, more active, and better educated than the population in general. Despite this limitation, we believe that the study still provides useful information regarding the psychometrics of the scale, and our stratified analyses provided no 
indication that the measure was less valid or reliable, for example, with less educated or more obese persons.

Several other limitations should be noted. First, our sample was somewhat more active than adults in general in South Carolina. According to the 2003 South Carolina BRFSS, $46 \%$ of adults are regularly active versus $52 \%$ in our sample. ${ }^{33}$ Second, we did not assess other psychological constructs that might be related to self-efficacy and would thus provide additional validation of the measure. Finally, in previous studies the Self-Efficacy for Exercise Questionnaire was administered via a paper-and-pencil questionnaire. It is not known whether the psychometric properties reported in this paper (i.e., collected via telephone) would be identical if the measure were administered via a paper-and-pencil questionnaire.

These limitations notwithstanding, our study provides useful information for researchers and interventionists who want to include measures of exercise self-efficacy in more diverse populations. The 14-item Self-Efficacy for Exercise Questionnaire yielded one factor that retained all items and was valid and reliable for use in adults who varied by age, gender, race, education, and body weight.

\section{Acknowledgments}

This research was funded by a cooperative agreement from the Centers for Disease Control and Prevention (U48/CCU409664 and R06/CCR421479). Its contents are solely the responsibility of the authors and do not necessarily represent the official views of the Centers for Disease Control and Prevention.

\section{References}

1. Bandura A. Social foundations of thought and action: a social cognitive theory. Englewood Cliffs, NJ: Prentice-Hall; 1986.

2. Bandura A. Self-efficacy mechanism in human agency. Am Psychol. 1982;37:122147.

3. Bandura A. Self-efficacy: toward a unifying theory of behavioral change. Psychol Rev. 1977;84:191-215.

4. Bandura A. Self-efficacy: the exercise of control. New York: W.H. Freeman Company; 1997.

5. Janz NK, Champion VL, Strecher VJ. The health belief model. In: Glanz K, Rimer BK, Lewis FM, eds. Health behavior and health education. Theory, research, and practice. 3rd ed. San Francisco, CA: Jossey-Bass; 2002:45-66.

6. Prochaska JO, DiClemente CC, Norcross JC. In search of how people change. Applications to addictive behaviors. Am Psychol. 1992;47:1102-1114.

7. Trost SG, Owen N, Bauman AE, Sallis JF, Brown W. Correlates of adults' participation in physical activity: review and update. Med Sci Sports Exerc. 2002;34:1996-2001.

8. Petosa RL, Suminski R, Hortz B. Predicting vigorous physical activity using social cognitive theory. Am J Health Behav. 2003;27:301-310.

9. Miller YD, Trost SG, Brown WJ. Mediators of physical activity behavior change among women with young children. Am J Prev Med. 2002;23:98-103.

10. Sternfeld B, Ainsworth BE, Quesenberry CP. Physical activity patterns in a diverse population of women. Prev Med. 1999;28:313-323. 
11. Eyler AA, Matson-Koffman D, Young DR, et al. Quantitative study of correlates of physical activity in women from diverse racial/ethnic groups. The Women's Cardiovascular Health Network Project summary and conclusions. Am J Prev Med. 2003;25: 93-103.

12. Conn VS. Older women: social cognitive theory correlates of health behavior. Wom Health. 1997;26:71-85.

13. McAuley E, Lox C, Duncan TE. Long-term maintenance of exercise, self-efficacy, and physiological change in older adults. J Gerontol. 1993;48:218-224.

14. McAuley E, Mihalko SL. Measuring exercise-related self-efficacy. In: Duda JL, ed. Advances in Sport and Exercise Psychology Measurement. Morgantown, WV: Fitness Information Technologies, Inc.; 1998:371-390.

15. Marcus BH, Selby VC, Niaura RS, Rossi JS. Self-efficacy and the stages of exercise behavior change. Res Q Exerc Sport. 1992;63:60-66.

16. Sallis JF, Pinski RB, Grossman RM, Patterson TL, Nader PR. The development of self-efficacy scales for health-related diet and exercise behaviors. Health Educ Res. 1988;3:283-292.

17. Resnick B, Jenkins LS. Testing the reliability and validity of the Self-Efficacy for Exercise scale. Nurs Res. 2000;49:154-159.

18. Garcia AW, King AC. Predicting long-term adherence to aerobic exercise: a comparison of two models. J Sport Exerc Psychol. 1991;13:394-410.

19. Brassington GS, Atienza AA, Perczek RE, DiLorenzo TM, King AC. Interventionrelated cognitive versus social mediators of exercise adherence in the elderly. Am J Prev Med. 2002;23:80-86.

20. Wilcox S, Bopp M, Oberrecht L, Kammermann SK, McElmurray CT. Psychosocial and perceived environmental correlates of physical activity in rural and older African American and white women. J Gerontol B Psychol Sci Soc Sci. 2003;58:P329P337.

21. Wilcox S, Storandt M. Relations among age, exercise, and psychological variables in a community sample of women. Health Psychol. 1996;15:110-113.

22. Conn VS. Older adults and exercise: path analysis of self-efficacy related constructs. Nurs Res. 1998;47:180-189.

23. Clark DO, Patrick DL, Grembowski D, Durham ML. Socioeconomic status and exercise self-efficacy in late life. J Behav Med. 1995;18:355-376.

24. Clark DO, Nothwehr F. Exercise self-efficacy and its correlates among socioeconomically disadvantaged older adults. Health Educ Behav. 1999;26:535-546.

25. Hays LM, Clark DO. Correlates of physical activity in a sample of older adults with type 2 diabetes. Diabetes Care. 1999;22:706-712.

26. Courneya KS, McAuley E. Efficacy, attributional, and affective responses of older adults following an acute bout of exercise. J Soc Behav Personal. 1993;8:729-742.

27. ORC MACRO. Participatory research for physical activity survey: Final report. Burlington, VT. July 22, 2003.

28. Strath SJ, Bassett DR, Jr., Ham SA, Swartz AM. Assessment of physical activity by telephone interview versus objective monitoring. Med Sci Sports Exerc. 2003;35: 2112-2118.

29. Pate RR, Pratt M, Blair SN, et al. Physical activity and public health. A recommendation from the Centers for Disease Control and Prevention and the American College of Sports Medicine. JAMA. 1995;273:402-407. 
30. Magee L. $\mathrm{R}^{2}$ measures based on Wald and likelihood ratio joint significance tests. Am Statistician. 1993;44:250-253.

31. Baranowski T, Anderson C, Carmack C. Mediating variable framework in physical activity interventions. How are we doing? How might we do better? Am J Prev Med. 1998;15:266-297.

32. Ainsworth BE, Wilcox S, Thompson WW, Richter DL, Henderson KA. Personal, social, and physical environmental correlates of physical activity in African-American women in South Carolina. Am J Prev Med. 2003;25:23-29.

33. Centers for Disease Control and Prevention. U.S. Physical Activity Statistics. Available at: http://www.cdc.gov/nccdphp/dnpa/physical/stats/us_physical_activity/. Accessed December 9, 2004. 